\title{
Patterns of responding differentiate intravenous nicotine self-administration from responding for a visual stimulus in $\mathrm{C57BL} / 6 \mathrm{~J}$ mice
}

\author{
Candice Contet $\cdot$ Kimberly N. Whisler $\cdot$ Holly Jarrell • \\ Paul J. Kenny • Athina Markou
}

Received: 30 March 2010 / Accepted: 3 July 2010 /Published online: 29 July 2010

(C) The Author(s) 2010. This article is published with open access at Springerlink.com

\begin{abstract}
Rationale Testing genetically engineered mice in a reliable nicotine self-administration procedure could provide important insights into the molecular mechanisms underlying nicotine reinforcement.

Objectives We assessed operant responding for intravenous nicotine infusions in $\mathrm{C} 57 \mathrm{BL} / 6 \mathrm{~J}$ male mice under a fixedratio 3 schedule of reinforcement in which a visual cue was contingently associated with drug delivery.

Methods/Results Acquisition, dose-response function, extinction, and cue-induced reinstatement of operant behavior
\end{abstract}

Electronic supplementary material The online version of this article (doi:10.1007/s00213-010-1950-4) contains supplementary material, which is available to authorized users.

C. Contet $\cdot$ K. N. Whisler $\cdot$ H. Jarrell $\cdot$ A. Markou $(\triangle)$

Department of Psychiatry, Mail Code 0603, School of Medicine, University of California San Diego,

9500 Gilman Drive,

La Jolla, CA 92093-0603, USA

e-mail: amarkou@ucsd.edu

P. J. Kenny

Department of Molecular Therapeutics,

The Scripps Research Institute-Scripps Florida,

130 Scripps Way,

Jupiter, FL 33458, USA

Present Address:

C. Contet

Committee on the Neurobiology of Addictive Disorders,

The Scripps Research Institute,

10550 North Torrey Pines Road,

La Jolla, CA 92037, USA

Present Address:

H. Jarrell

Section of Neurobiology, Division of Biological Sciences,

University of California, San Diego,

La Jolla, CA 92093, USA were characterized. Low nicotine doses (0.001-0.06 mg/kg/ infusion) elicited response rates similar to those supported by saline, whereas a higher dose $(0.1 \mathrm{mg} / \mathrm{kg} /$ infusion $)$ decreased responding. Using an identical procedure to assess cocaine self-administration in an independent group of mice yielded an inverted U-shaped dose-response curve. Other mice trained to respond exclusively for the visual stimulus earned a similar number of reinforcers as mice self-administering saline or low nicotine doses, although with a lower selectivity for the active lever and their response rates were sensitive to the discontinuation and resumption of cue light presentation. Finally, patterns of responding for nicotine, cocaine, or the visual stimulus alone were analyzed using frequency distributions of interresponse intervals and extended return maps. These analyses revealed unique properties of nicotine, which dose-dependently delayed the first response post-timeout and increased the regularity of lever pressing activity. Conclusions Nicotine did not enhance the reinforcing properties of the visual cue paired with drug delivery. Interestingly, however, patterns of responding could differentiate nicotine self-administration from responding for a visual stimulus or saline and indicated that nicotine functioned as a salient stimulus driving highly regular operant behavior.

Keywords Nicotine self-administration $\cdot$ Cue $\cdot$ C57BL/6J mice $\cdot$ Patterns of responding - Inter-response intervals . Extended return map

\section{Introduction}

Tobacco use is the leading cause of preventable death worldwide and is currently responsible for 5.4 million 
deaths yearly (WHO 2008). The maintenance of tobacco smoking is partly attributable to the highly addictive properties of nicotine (Hatsukami et al. 2008; Stolerman and Jarvis 1995). The neurobiological mechanisms underlying the development of dependence to nicotine have been extensively explored using pharmacological approaches in rat models (see Markou 2008 for review). Nevertheless, the availability of genetically engineered mice provides unique opportunities to further explore the molecular basis of nicotine dependence. The vast majority of nicotine selfadministration studies in mice have used voluntary oral intake procedures that do not involve instrumental learning and therefore do not directly probe the motivational aspects of nicotine consumption (e.g., Adriani et al. 2002; Robinson et al. 1996). Consequently, a number of laboratories have implemented an operant procedure of drug administration through the lateral tail vein in which the nose-poke responses of a "master" mouse control the delivery of nicotine infusions to itself and a paired "yoked" mouse (e.g., Criswell 1982; Martellotta et al. 1995; Paterson et al. 2003; Semenova et al. 1995). This procedure, however, presents major limitations. First, each individual mouse can only perform a limited number of self-administration sessions and experiments using this technique necessitate the use of hundreds of mice (e.g., Paterson et al. 2003), which is impractical particularly in the case of genetically engineered animals. Additionally, this method involves the partial restraint of the mouse, which may lead to stress-related effects.

Subsequent efforts have been directed towards the development of a reliable procedure of intravenous nicotine self-administration in chronically catheterized mice, but this has proven challenging. Previous attempts were biased by the fact that mice were initially trained to respond for another reinforcer, such as cocaine, water, or food, before being switched to nicotine (Bilkei-Gorzo et al. 2008; Epping-Jordan et al. 1999; Picciotto et al. 1998; Stolerman et al. 1999). Acquisition of operant conditioning using an alternative positive reinforcer, especially a drug of abuse, is likely to induce neuroadaptive changes in brain reward systems, including the cholinergic pathways, thereby altering subsequent responding for nicotine reinforcement (Williams and Adinoff 2008). Recent endeavors to circumvent this drawback have entailed the use of less demanding response requirements (i.e., nose-poking under a continuous schedule of reinforcement), paired with the contingent presentation of environmental cues to signal nicotine delivery (Galeote et al. 2009; Martin-Garcia et al. 2009; Plaza-Zabala et al. 2010).

The aim of the present study was to develop a reliable and unbiased procedure for intravenous nicotine selfadministration in freely moving $\mathrm{C} 57 \mathrm{BL} / 6 \mathrm{~J}$ mice that could be applied in genetically engineered animals. Nicotine dose-effect function, extinction of responding, and cueinduced reinstatement were characterized. Patterns of responding were also analyzed in detail. As a positive control for our experimental procedures, we assessed intravenous cocaine self-administration under identical conditions in an independent cohort of mice. Finally, we evaluated operant responding for the presentation of a visual stimulus in a separate group of mice trained to respond exclusively for the light cue contingently associated with drug delivery in the mice tested for nicotine and cocaine self-administration.

\section{Materials and methods}

Animals

Male C57BL/6J mice (Jackson, Sacramento, CA, USA) were maintained in a 12-h light/dark cycle (lights on at $07: 00 \mathrm{pm})$ in a temperature- $\left(72^{\circ} \mathrm{F}\right)$ and humidity-controlled $(50 \%)$ vivarium. Mice were obtained at 8 weeks of age and acclimated for a minimum of 7 days to their new environment before undergoing surgery. After surgery, mice were individually housed to prevent damage to the catheter. Water was available ad libitum, except during the 1-h self-administration sessions. Mice were fed ad libitum with standard rodent chow (Harlan Teklad, Frederick, MD, USA) until the day before self-administration sessions started, and they were then given 3.8-4.2 $\mathrm{g}$ of food pellets once daily after the session (approximately $85 \%$ of ad libitum intake). Testing was conducted during the dark phase of the circadian cycle. All procedures were carried out in accordance with the National Institutes of Health Guide for the Care and Use of Laboratory Animals and were approved by the University of California San Diego Institutional Animal Care and Use Committee.

\section{Drugs}

(-)-Nicotine hydrogen tartrate salt (Sigma-Aldrich, St. Louis, MO, USA) was dissolved in physiological saline $(0.9 \%$; Hospira, Lake Forest, IL, USA) at a concentration of $0.3 \mathrm{mg} / \mathrm{ml}$. The $\mathrm{pH}$ was adjusted to $7.2 \pm 0.2$ using sodium hydroxide, and the solution was sterilized through a 0.22 $\mu \mathrm{m}$ syringe filter. The stock solution was stored in a glass bottle for up to 1 week, and dilutions adjusted to the body weight of each mouse were prepared daily. Cocaine hydrochloride (Sigma-Aldrich) was dissolved in physiological saline at a concentration of $2 \mathrm{mg} / \mathrm{ml}$, and dilutions adjusted to the body weight of each mouse were prepared daily. All nicotine doses are expressed as free-base concentrations, and cocaine doses as salt concentrations. Heparinized saline was prepared by adding heparin 
(Abraxis Pharmaceutical Products, Schaumburg, IL, USA) to bacteriostatic saline (Hospira) at a concentration of 60 USP units per milliliter. Isoflurane was obtained from Minrad (Orchard Park, NY, USA). Flunixin $50 \mathrm{mg} / \mathrm{ml}$ (MWI Veterinary Supply, Meridian, ID, USA) was diluted 200 times in saline for injection. Timentin (GlaxoSmithKline, Coraopolis, PA, USA) was dissolved in heparinized saline at a concentration of $0.1 \mathrm{mg} / \mathrm{ml}$ Baytril (Bayer, Shawnee Mission, KS, USA) and diluted in heparinized saline at a concentration of $5 \mathrm{mg} / \mathrm{ml}$. Ketamine hydrochloride (Fort Dodge Animal Health, Fort Dodge, IA, USA) and midazolam (Baxter Healthcare, Deerfield, IL, USA) were mixed in saline at final concentrations of 5 and $0.25 \mathrm{mg} / \mathrm{ml}$, respectively.

Surgery and operant conditioning apparatus

Details can be found in Supplementary Methods.

Intravenous drug self-administration

Experiment 1: Acquisition, generation of dose-response function, extinction, and reinstatement of intravenous selfadministration of nicotine or cocaine under a fixed-ratio 3 schedule of reinforcement A cohort of 25 mice was trained to self-administer nicotine at a dose of $0.03 \mathrm{mg} / \mathrm{kg} /$ infusion (18 $\mu$ l delivered over $1 \mathrm{~s}$ ) under a fixed-ratio 1 (FR1) timeout (TO) 20-s schedule of reinforcement during 1-h sessions conducted 5 days per week. Responding on one of the two levers was reinforced by a drug infusion (active lever), while responding on the other lever was recorded but had no scheduled consequences (inactive lever). To minimize bias due to position preference, the side assignment (left or right) of the active and inactive levers was counterbalanced among mice. The light cue located above the active lever was turned on at the beginning of the infusion (1 s) and remained lit during the time-out period (20 s) to signal drug delivery. The criteria for acquisition were the following: (1) at least 10 infusions earned per session, (2) at least $70 \%$ selectivity for the active lever over the inactive lever, and (3) no more than $20 \%$ variability in the number of infusions earned over two consecutive sessions. Once the acquisition criteria were met, the response requirement was increased to FR3 until criteria 2 and 3 were met. Saline was then substituted for nicotine until stable responding was achieved (less than $20 \%$ variability over two consecutive sessions). A dose-response function was then generated according to a within-subjects design by giving each mouse access to different doses of nicotine $(0,0.01$, $0.02,0.03,0.06$, and $0.1 \mathrm{mg} / \mathrm{kg} /$ infusion) in a pseudorandom order as described below. Specifically, the training dose $(0.03 \mathrm{mg} / \mathrm{kg} /$ infusion $)$ was the first and last dose to be presented to each mouse to ensure that responding was reinforced with nicotine after the saline substitution phase and before the transition to the extinction phase. Data plotted on the graphs for the $0.03 \mathrm{mg} / \mathrm{kg} /$ infusion dose correspond to the last presentation of the training dose. The remaining nicotine doses were presented according to a Latin-square design. Each nicotine dose was available until the stability criterion was met (less than 20\% variability over two consecutive sessions). A priming infusion was delivered at the beginning of each session during the dose-response function determination to expose the mouse to the dose available during that session. For all doses (including saline), completion of the FR3 resulted in the delivery of an infusion and illumination of the cue light for $20 \mathrm{~s}$ during which lever presses were counted but had no scheduled consequences (TO $20 \mathrm{~s}$ ). A total of 13 mice completed the dose-response phase (i.e., 13 mice had a functional catheter for 10 weeks or more of testing). Mice then proceeded to the extinction phase. During the 19 1 -h extinction sessions, mice were not tethered, and pressing the active lever did not result in the presentation of the stimulus light or the pump sound. Finally, one test of cue-induced reinstatement was conducted on the day after the 19 th extinction session. During the $1-\mathrm{h}$ reinstatement session, mice were tethered, and the stimulus light and pump sound were presented according to an FR3 TO 20-s schedule, but no infusion was actually delivered because several of the mice no longer had functional catheters. Extinction and reinstatement data were collected for 10 mice.

An identical experiment was simultaneously conducted in an independent cohort of 17 mice self-administering cocaine. The training dose was $0.3 \mathrm{mg} / \mathrm{kg} /$ infusion, and the dose-response included cocaine doses of $0,0.01,0.03,0.1$, $0.2,0.3,1$, and $3 \mathrm{mg} / \mathrm{kg} /$ infusion. A total of nine mice completed the cocaine dose-response function, eight of which underwent the extinction and cue-induced reinstatement phases.

Experiment 2: Self-administration of low doses of nicotine An independent cohort of mice $(n=37)$ was used to assess whether reliable nicotine self-administration may be detected using doses of nicotine lower than $0.01 \mathrm{mg} / \mathrm{kg} /$ infusion. Although the experimental timeline was essentially the same as in experiment 1 , a number of modifications were implemented. To expedite data collection, mice were maintained on an FR1 schedule of reinforcement throughout the experiment. The training dose was $0.01 \mathrm{mg} / \mathrm{kg} /$ infusion, and the dose-response included the following nicotine doses: $0,0.001,0.003,0.06$, and $0.1 \mathrm{mg} / \mathrm{kg} /$ infusion. The saline substitution phase was limited to three sessions, after which the training dose was presented for three sessions. Determination of the dose-response function was then initiated. Each nicotine dose (including saline) 
was available for one session (no stability criterion), and between each of these doses, mice were allowed to selfadminister the training dose for one session. A priming infusion was delivered at the beginning of each session during the dose-response determination. A total of 10 mice completed the dose-response determination.

Experiment 3: Operant responding for a visual stimulus A separate group of mice $(n=10)$ that did not undergo surgery was trained to lever press for the visual stimulus using acquisition criteria identical to those described in experiment 1 . Mice were then exposed to 10 extinction sessions, followed by one test of cue-induced reinstatement. Seven mice met the acquisition criteria, and extinction and reinstatement data were collected for six mice.

Analyses of patterns of responding

Frequency distribution of inter-response intervals Interresponse intervals (IRIs) were extracted from MedPC IV raw data files (Med Associates). Data from the 13 mice that completed the nicotine dose-response phase in experiment 1 were examined using files corresponding to the last selfadministration session of $0,0.01,0.03$, and $0.1 \mathrm{mg}$ nicotine/ $\mathrm{kg} /$ infusion. Likewise, data from the nine mice that completed the cocaine dose-response phase in experiment 1 were examined using files corresponding to the last selfadministration session of $0,0.01,0.1,1$, and $3 \mathrm{mg}$ cocaine/ $\mathrm{kg} /$ infusion. Data from the last acquisition session of the mice trained to respond for the visual stimulus (experiment $3, n=7$ ) were also analyzed. Lever presses during the timeout period were excluded, as well as the lever presses preceding the first infusion of the session. The remaining responses were sorted into "first" and "second and third" post-timeout responses. The time-out duration $(20 \mathrm{~s})$ was subtracted from the first IRI. These two series of values were then analyzed for relative frequency distribution. A preliminary analysis based on 20 -s bins indicated that nicotine primarily altered IRIs shorter than $60 \mathrm{~s}$ and IRIs longer than $240 \mathrm{~s}$. Relative frequencies are therefore presented for IRIs below $60 \mathrm{~s}$, between 60 and $240 \mathrm{~s}$, and above $240 \mathrm{~s}$.

Return maps of inter-response intervals and running averages The serial temporal organization of the same sequences of IRIs was analyzed using extended return maps. Standard return maps consist of plotting IRIs against preceding IRIs to examine the regularity of the observed behavior. The lag value of a return map designates the shift between the IRI used as the ordinate and the IRI used as the abscissa. Thus, a lag $L$ return map uses the following equation: $\mathrm{IRI}_{n+L}=f\left(\mathrm{IRI}_{n}\right)$. Extended return maps have been developed to improve the analyzing ability of return maps for data strongly contaminated with noise and have proven well-suited to uncover dynamic patterns of operant behavior ( $\mathrm{Li}$ and Huston 2002). To this end, running averages (RAs) are used instead of IRIs themselves. The fold $F$ of an extended return map specifies the range within which the $\mathrm{RA}$ is computed, according to ${ }^{F} \mathrm{RA}_{n}=\mathrm{IRI}_{n}+\mathrm{IRI}_{n+1}+$ IRI $_{n+2}+\ldots+$ IRI $_{n+F-1}$. A lag $L$ fold $F$ extended return map uses the following equation: ${ }^{F} \mathrm{RA}_{n+L}=f\left(\mathrm{RA}_{n}\right)$. Standard return maps are considered to have a fold value of 1 . In our case, the frequency distribution analysis indicated a bimodal distribution of the IRIs, with the first IRIs posttimeout being significantly longer than the second and third IRIs. Standard return maps with a lag value of 3 were therefore plotted according to the equation $\operatorname{IRI}_{n+3}=f\left(\mathrm{IRI}_{n}\right)$. New data sets were then generated, consisting of the fold 3 running averages of the original IRIs according to the following formula: ${ }^{3} \mathrm{RA}_{n}=\mathrm{IRI}_{n}+\mathrm{IRI}_{n+3}+\mathrm{IRI}_{n+6}$ (so that the first, second, and third IRIs post-timeout were averaged separately). Extended return maps with a fold of 3 (and a lag of 3) were then plotted according to the equation ${ }^{3} \mathrm{RA}_{n+3}=f\left({ }^{3} \mathrm{RA}_{n}\right)$. Likewise, fold 5 RAs were calculated $\left({ }^{5} \mathrm{RA}_{n}=\mathrm{IRI}_{n}+\mathrm{IRI}_{n+3}+\mathrm{IRI}_{n+6}+\mathrm{IRI}_{n+9}+\mathrm{IRI}_{n+12}\right)$, and fold 5 (lag 3) extended return maps were plotted according to ${ }^{5} \mathrm{RA}_{n+3}=f\left({ }^{5} \mathrm{RA}_{n}\right)$. Higher-fold maps were not generated because IRI sequences for some mice at the highest nicotine and cocaine doses were too short to calculate fold 6 and higher RAs.

\section{Statistical analyses}

Statistical analyses were performed using GraphPad Prism version 4.03 (GraphPad Software, La Jolla, CA, USA). Attrition and acquisition rates were compared using the $\chi^{2}$ test. All other data were first subjected to the KolmogorovSmirnov normality test to determine whether they followed a Gaussian or non-parametric distribution, and the appropriate statistical test was subsequently selected. The numbers of sessions to criterion were analyzed using twotailed Student's $t$ test or Mann-Whitney test for unpaired samples. Normally distributed data from the dose-response studies and from the IRI frequency distribution were subjected to a one-way repeated-measures analysis of variance (ANOVA), with nicotine or cocaine dose as the within-subjects factor. When appropriate, multiple comparisons were performed using Dunnett's test (with saline as the control condition). When data were non-parametric, Friedman's test was applied and followed, when appropriate, by Dunn's multiple comparisons. Data from the extinction phase were also analyzed using repeatedmeasures ANOVA or Friedman's test, with extinction session as the within-subjects factor. Data from the last 
extinction session were compared with the mean values of the last two sessions before extinction and with data from the cue-induced reinstatement session using Student's $t$ test or the Wilcoxon signed-rank test for matched samples. Two-way repeated-measures ANOVAs were used to compare data of the two nicotine dose-response functions generated under the FR schedule. Differences in the frequency distribution of the first and the second and third IRIs were examined using two-way repeated-measures ANOVA, with nicotine dose as the within-subjects factor. Return maps were analyzed using linear regression. Data from all mice were collapsed into a single sequence of IRIs or RAs for a given experimental condition to generate the associated standard or extended return maps. Slopes, intercepts, and goodness of fit $\left(r^{2}\right)$ obtained for each fitted line of the return maps were then subjected to two-way ANOVA without replication (McDonald 2009), using nicotine or cocaine dose and return map fold as variables. To further analyze the main effects of nicotine dose on the slope and goodness of fit, individual regression lines were generated for each mouse and the latter parameters were analyzed using one-tailed Student's $t$ test or Wilcoxon test for matched pairs. The level of statistical significance was set at 0.05 .

\section{Results}

\section{Experiment 1}

\section{C57BL/6J mice learned to self-administer cocaine faster than nicotine}

Mice trained to self-administer cocaine required significantly fewer sessions to reach the acquisition criteria on an FR3 schedule than mice trained to self-administer nicotine (Mann-Whitney test, $U=9, p \leq 0.001$; Fig. 1). However, mice responding for nicotine and for cocaine both needed a similar number of sessions to stabilize their response rates during the saline substitution phase (Supplementary Figure S1). Finally, the average number of sessions that were necessary to meet the stability criterion for each dose of the dose-response function was significantly smaller for the mice self-administering cocaine than for the mice selfadministering nicotine (unpaired $t$ test, $t_{20}=3.36, p<0.01$; Supplementary Figure S1).

Attrition rates due to acquisition failure, catheter dysfunction, or health degradation were comparable between the two cohorts. Of the 25 mice initially trained to self-administer nicotine, four $(16 \%)$ failed to meet the acquisition criteria, eight $(32 \%)$ were excluded due to catheter leakage or sickness, and $13(52 \%)$ completed the dose-response function. Of the 17 mice initially trained to self-administer cocaine, three $(18 \%)$ did not acquire self-
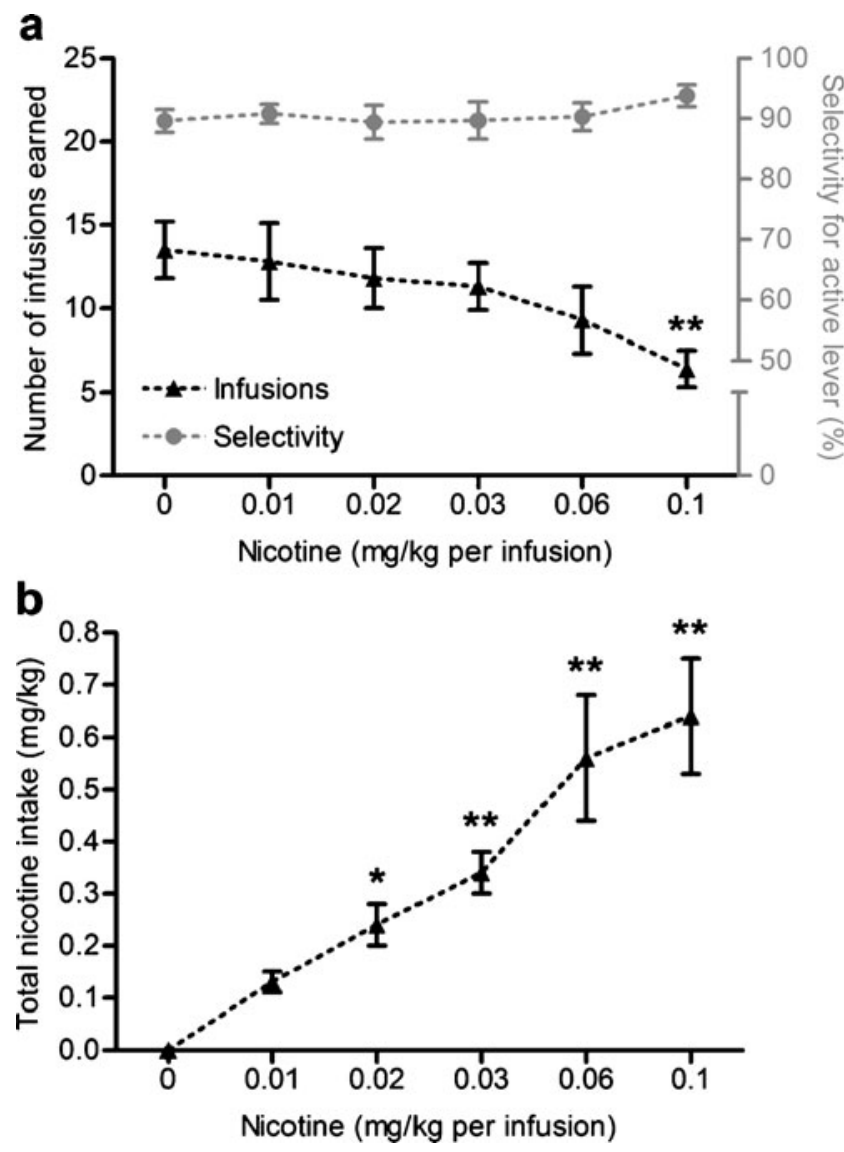

Fig. 1 Experiment 1. Dose-response curve of intravenous nicotine self-administration under a fixed-ratio 3 (FR3) schedule of reinforcement. a Number of reinforcers earned during the 1-h selfadministration session (lower black trace, left Y-axis) and selectivity for the active lever (upper gray trace, right Y-axis). b Total nicotine intake expressed in milligrams nicotine per kilogram body weight. Results are expressed as mean \pm SEM $(n=13)$. Data were subjected to repeated-measures ANOVA or Friedman's test followed by post hoc comparisons with the $0 \mathrm{mg} / \mathrm{kg} /$ infusion dose (saline infusion; ${ }^{*} p<$ $0.05, * * p<0.01)$

administration, five (29\%) had compromised catheters or health conditions, and nine (53\%) completed the entire dose-response function.

\section{High dose of nicotine led to decreased response rates}

Figure 1a (lower black trace) shows the dose-effect curve of responding for nicotine concentrations ranging from 0.01 to $0.1 \mathrm{mg} / \mathrm{kg} /$ infusion under an FR3 schedule of reinforcement. A repeated-measures ANOVA revealed a significant main effect of nicotine dose $\left(F_{5,60}=4.08, p<0.01\right)$. Although none of the doses led to an increased number of earned infusions compared with saline, responding was significantly lower for the $0.1 \mathrm{mg} / \mathrm{kg} /$ infusion dose $(p<0.01)$. This decrease in responding reflected an adjustment of the total nicotine intake consumed during the 1-h session, in which mice actually self-administered 
increasing amounts of nicotine with ascending concentrations (repeated-measures ANOVA, $F_{5,60}=17.85, p<0.001$; Fig. 2b). High selectivity for the active lever was maintained for all nicotine doses, including saline (Fig. 1a, upper gray trace).

\section{Selectivity for the nicotine-associated lever decreased during the extinction phase and was restored during the cue-induced reinstatement session}

Although no main effect of session was observed on the number of presses on the active lever across the extinction phase, presses on the inactive lever significantly increased over time (Friedman test, $Q_{18}=42.25, p \leq 0.001$ ), consistent with a simultaneous decrease in selectivity for the active lever (repeated-measures ANOVA, $F_{18,162}=1.83, p<0.05$; Fig. 3). Accordingly, responding during the last extinction session (session 19) was significantly different from responding during the last two self-administration sessions (nicotine $0.03 \mathrm{mg} / \mathrm{kg} /$ infusion; indicated as "Pre" in Fig. 2) for both inactive lever presses (paired $t$ test, $t_{9}=3.01, p<$ 0.05 ) and selectivity (Wilcoxon test, $W=47, p<0.05$ ), but not for active lever presses (Fig. 2).

Response-contingent presentation of nicotine-associated cues during the reinstatement session led to a marked, though variable, increase in the mean number of responses emitted on the active lever (Wilcoxon test, $W=-38, p<$ 0.05 ) but did not affect the number of responses on the inactive lever compared with the last extinction session (Fig. 2). Consequently, selectivity for the active lever also improved (paired $t$ test, $t_{9}=2.46, p<0.05$; Fig. 2).
To dissociate responding for the cue light from nicotine seeking, we analyzed the effect of withholding and reinstating nicotine delivery while the visual stimulus was still contingently presented. For that purpose, responding at the beginning and the end of the saline substitution phase (nicotine withheld, indicated as "Sal First" and "Sal Last" in Supplementary Figure S2a) was compared to the preceding and following self-administration sessions (nicotine $0.03 \mathrm{mg} / \mathrm{kg} /$ infusion, indicated as "Nic Pre" and "Nic Post" in Supplementary Figure S2a). Interestingly, both response rates and selectivity were insensitive to the removal and subsequent resumption of nicotine delivery (Supplementary Figure S2a).

\section{Cocaine self-administration produced an inverted U-shaped dose-response curve}

To ensure that our experimental conditions were appropriate for detecting the reinforcing effects of a drug, we generated a cocaine dose-effect function in an independent cohort of mice trained to self-administer cocaine at a dose of $0.3 \mathrm{mg} / \mathrm{kg} /$ infusion (Fig. 3). Repeated-measures ANOVA revealed a main effect of cocaine dose $\left(F_{7,56}=16.72, p<0.001\right)$. Post hoc analyses indicated that mice earned more infusions when selfadministering cocaine doses between 0.03 and $0.3 \mathrm{mg} / \mathrm{kg} /$ infusion than when self-administering saline $(p<0.01)$. However, self-administration of the highest cocaine dose ( $3 \mathrm{mg} / \mathrm{kg}$ /infusion) resulted in a significant decrease in responding compared with saline $(p<0.05)$. Thus, cocaine self-administration under experimental conditions identical to those used for nicotine self-administration yielded a typical

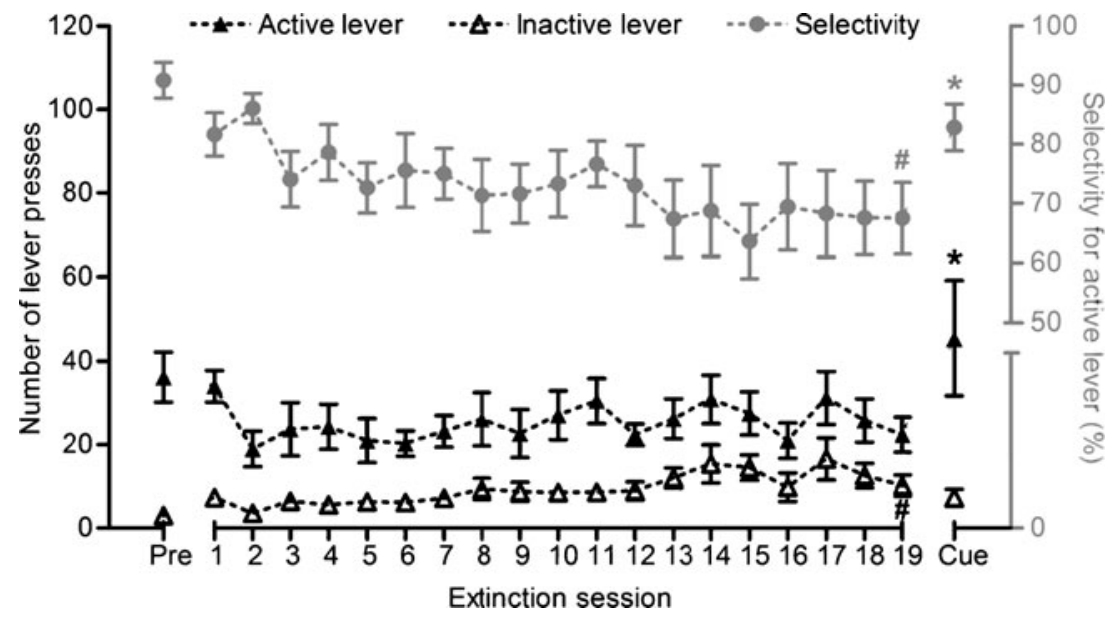

Fig. 2 Experiment 1. Extinction and cue-induced reinstatement of nicotine seeking. The graph shows mean $\pm \operatorname{SEM}(n=10)$ of responses on the active lever (black triangles, left Y-axis), responses on the inactive lever (white triangles, left Y-axis), and selectivity for the active lever (gray circles, right Y-axis). The "Pre" data represent the average of the last two sessions of nicotine $(0.03 \mathrm{mg} / \mathrm{kg})$ selfadministration collected at the end of the dose-response phase immediately before the extinction phase began. Extinction data were subjected to repeated-measures ANOVA or Friedman's test, and data from the 19th extinction session were compared with data from the last two self-administration sessions (Pre, ${ }^{*} p<0.05$ ) and from the cueinduced reinstatement session (Cue, $\left.{ }^{*} p<0.05\right)$ using paired $t$ test or Wilcoxon test 

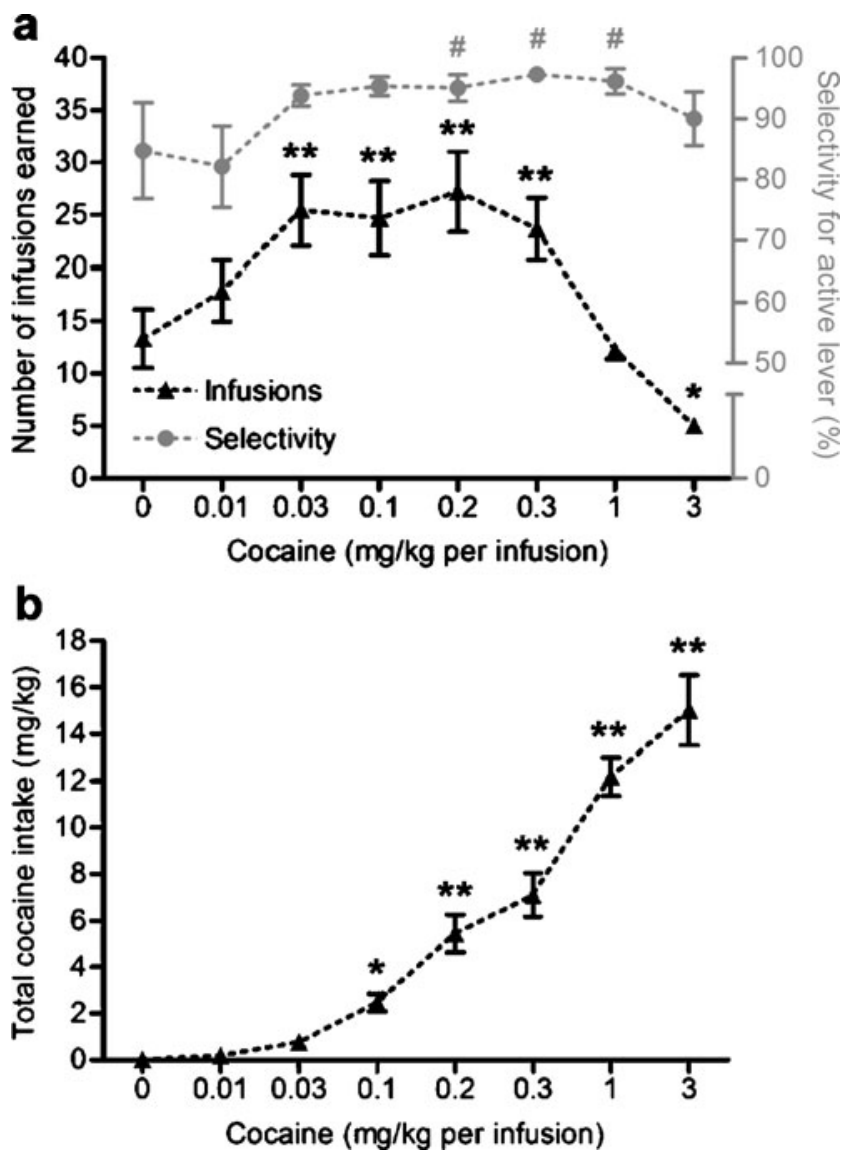

Fig. 3 Experiment 1. Dose-response curve of intravenous cocaine self-administration under a fixed-ratio 3 (FR3) schedule of reinforcement. a Number of reinforcers earned during the 1-h selfadministration session (lower black trace, left Y-axis) and selectivity for the active lever (upper gray trace, right Y-axis). b Total cocaine intake expressed in milligrams cocaine per kilogram body weight. Results are expressed as mean \pm SEM $(n=9)$. Data were subjected to repeated-measures ANOVA or Friedman's test followed by post hoc comparisons with the $0 \mathrm{mg} / \mathrm{kg} /$ infusion dose (saline infusion; ${ }^{*} p<$ $\left.0.05,{ }^{* *} p<0.01\right)$ and $0.01 \mathrm{mg} / \mathrm{kg} /$ infusion dose $\left({ }^{\#} p<0.05\right)$

inverted U-shaped dose-response curve (Fig. 3a, lower black trace). This dose-response function translated to a monotonic increasing function in terms of total amount of cocaine selfadministered $\left(F_{7,56}=83.50, p<0.001\right.$; Fig. $\left.3 \mathrm{~b}\right)$, indicating that mice adjusted their responding to titrate their intake.

Selectivity for the active lever, although consistently above $80 \%$, was also sensitive to the dose of cocaine (Friedman test, $Q_{7}=20.30, p<0.01$ ) and was higher for doses between 0.2 and $1 \mathrm{mg} / \mathrm{kg} /$ infusion than for the $0.01 \mathrm{mg} / \mathrm{kg} /$ infusion dose (Fig. 3a, upper gray trace).

\section{Responding on the cocaine-reinforced lever diminished during extinction and was reinstated upon presentation of cocaine-associated cues}

The number of responses on the active lever significantly decreased during the extinction phase (Friedman test, $Q_{18}=$
34.58, $p \leq 0.01$ ) and showed a dramatic reduction across the first three extinction sessions (Fig. 4). However, inactive lever presses and selectivity for the active lever remained unaltered. On the last day of extinction (session 19), both the number of active lever presses and selectivity were lower than on the last two self-administration sessions (cocaine $0.3 \mathrm{mg} / \mathrm{kg} /$ infusion; indicated as "Pre" in Fig. 4), while the number of inactive lever presses did not differ (paired $t$ tests, $t_{7}=7.68, p<0.001, t_{7}=3.05, p<0.05$, and n.s., respectively).

Cue-induced reinstatement led to a significant increase in active lever presses (paired $t$ test, $t_{7}=2.74, p<0.05$ ) but did not impact responding on the inactive lever or selectivity compared with the last extinction session (Fig. 4).

Extinction of responding for cocaine also occurred during the saline substitution phase, as response rates decreased (paired $t$ test, $t_{8}=3.19, p<0.05$ ) and selectivity tended to decline (paired $t$ test, $t_{8}=2.13, p=0.07$ ) despite the contingent presentation of the visual stimulus (see Supplementary Figure S2b, "Coc Pre" vs "Sal Last"). Resuming cocaine delivery restored selectivity (paired $t$ test, $t_{8}=6.36, p<0.001$ ) but did not affect response rates (see Supplementary Figure S2b, "Sal Last" vs "Coc Post").

\section{Experiment 2}

\section{Further decreases in nicotine dose did not increase} self-administration rates, but the highest nicotine dose reproducibly decreased responding

To assess whether the ascending limb of a putative inverted U-shaped dose-response curve may have been missed in experiment 1 due to the use of a narrow range of nicotine doses that could have been relatively high, lower nicotine doses were tested (Fig. 5). Similar to experiment 1 (Fig. 1a), a main effect of dose was detected (repeatedmeasures ANOVA, $F_{5,45}=3.37, p<0.05$ ), but no nicotine dose increased responding above saline-maintained responding, and availability of the $0.1 \mathrm{mg} / \mathrm{kg} /$ infusion nicotine dose again resulted in a decreased number of earned infusions compared with saline $(p<0.05$; Fig. 5, lower black trace). As previously observed, selectivity for the active lever was not affected by nicotine dose (Fig. 5, upper gray trace).

Decreasing the response requirement (FR1 in experiment 2 vs FR3 in experiment 1) resulted in slightly higher responding overall (compare Figs. 1a and 5), but the difference between the numbers of infusions earned for the same nicotine doses (i.e., $0,0.01,0.06$, and $0.1 \mathrm{mg} / \mathrm{kg} /$ infusion) under the two different FRs did not reach statistical significance. A main effect of nicotine dose was observed $\left(F_{3,21}=9.69, p<0.001\right)$, and post hoc tests indicated that response rates decreased at the $0.1 \mathrm{mg} / \mathrm{kg} /$ infusion nicotine 


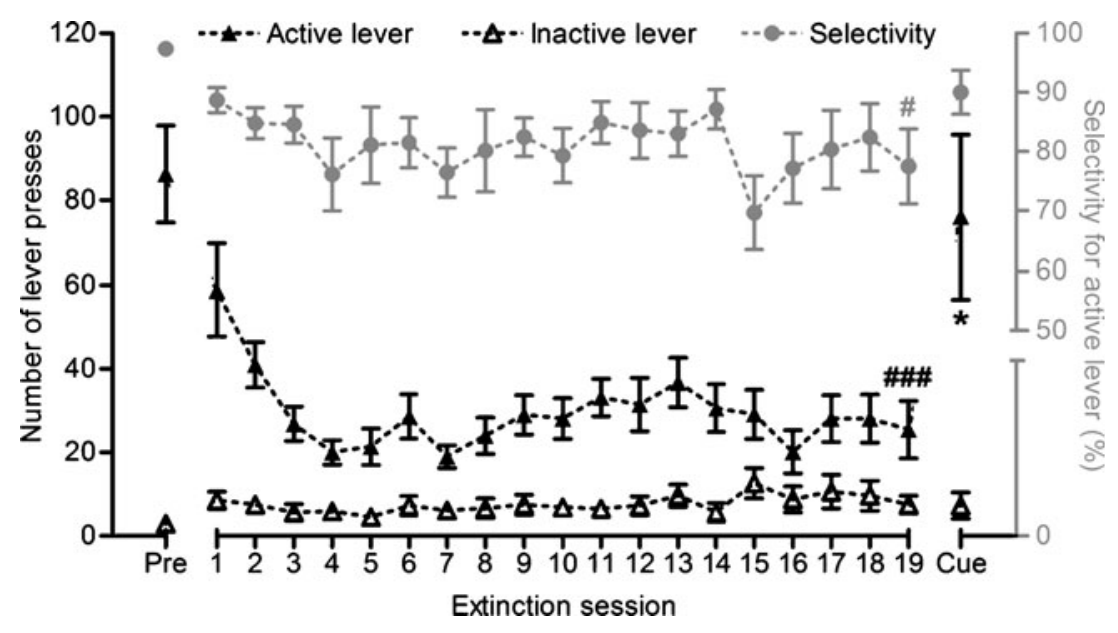

Fig. 4 Experiment 1. Extinction and cue-induced reinstatement of cocaine seeking. The graph shows mean $\pm \operatorname{SEM}(n=8)$ of responses on the active lever (black triangles, left Y-axis), responses on the inactive (gray circles, right Y-axis). The "Pre" data represent the average of the last two sessions of cocaine $(0.3 \mathrm{mg} / \mathrm{kg})$ self-administration collected lever (white triangles, left Y-axis), and selectivity for the active lever

at the end of the dose-response phase immediately before the extinction phase began. Extinction data were subjected to Friedman's test, and data from the 19th extinction session were compared with data from the last two self-administration sessions (Pre, ${ }^{\#} p<0.05$,

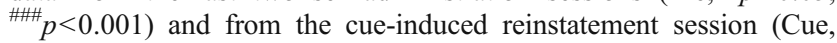
$* p<0.05)$ using paired $t$ tests

cantly lower than selectivity of nicotine-self-administering mice $\left(91.5 \pm 1.9 \%\right.$; unpaired $t$ test, $\left.t_{18}=2.80, p<0.05\right)$. Interestingly, mice self-administering saline during the dose-response phase of experiment 1 also earned a similar number of reinforcers (13.5 \pm 1.7 infusions, unpaired $t$ test, n.s.) and showed higher selectivity for the active lever (89.6 $\pm 1.9 \%$; unpaired $t$ test, $\left.t_{18}=2.29, p<0.05\right)$ than mice exclusively lever pressing for the cue light in experiment 3 .

During the extinction phase (Fig. 6), a strong trend toward a main effect of session was found on the number of responses on the active lever (repeated-measures ANOVA,

To assess the possibility that responding was primarily motivated by the visual stimulus presented upon infusion delivery, experimental conditions identical to those in experiment 1 were used to measure the level of behavior maintained by the light cue alone. Of the 10 mice trained to lever press for the light cue, seven met the acquisition criteria after an average of $19.6 \pm 2.9$ sessions. This rate of successful acquisition (70\%) was comparable to the rate achieved by mice trained to lever press for nicotine in experiment 1 (13 of 17 mice, $76.5 \%$ ), when not taking into account the mice excluded due to catheter or health concerns, given that these instances were related to the surgical procedure not undergone by mice in experiment 3 . The number of sessions required to meet the acquisition criteria was not significantly different between the two

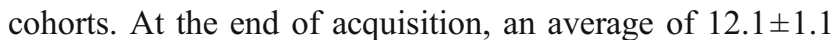
reinforcers (cue light presentations) was obtained, which did not differ from the $13.0 \pm 1.6$ infusions earned by nicotine self-administering mice by the end of the acquisition phase $(0.03 \mathrm{mg} / \mathrm{kg} /$ infusion $)$ in experiment 1 . However, selectivity for the active lever $(82.1 \pm 2.8 \%)$ was signifi-
Fig. 5 Experiment 2. Dose-response curve of intravenous nicotine self-administration under a fixed-ratio 1 (FR1) schedule of reinforcement. The graph shows the number of reinforcers earned during the 1-h self-administration session (lower black trace, left $Y$-axis) and the selectivity for the active lever (upper gray trace, right Y-axis). Results are expressed as mean \pm SEM $(n=10)$. Data were subjected to repeated-measures ANOVA or Friedman's test followed by post hoc comparisons with the $0 \mathrm{mg} / \mathrm{kg} /$ infusion dose (saline infusion; $* p<0.05)$

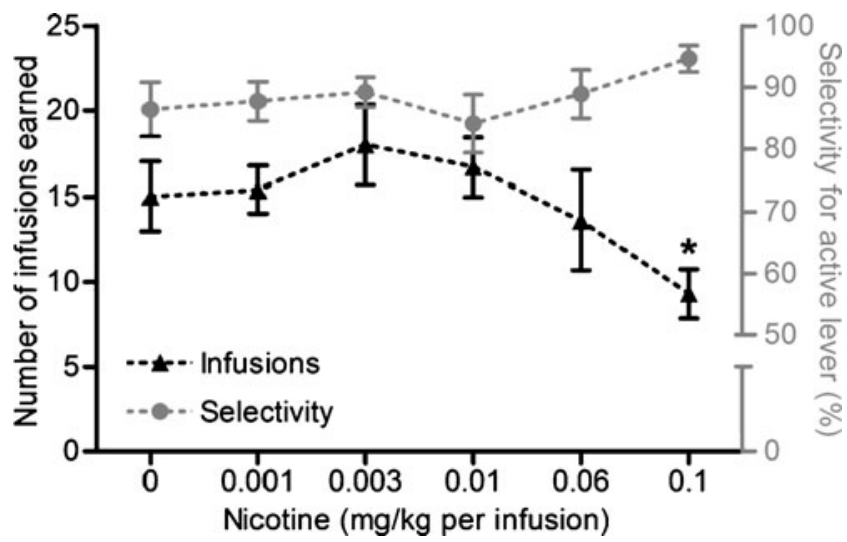




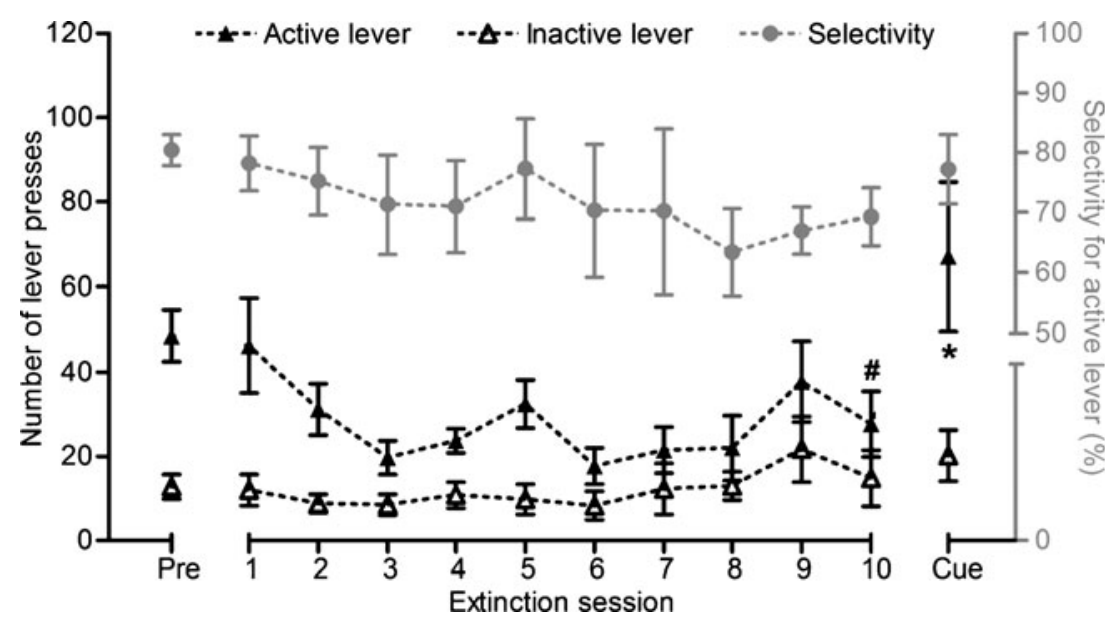

Fig. 6 Experiment 3. Extinction and cue-induced reinstatement of visual stimulus seeking. The graph shows the mean \pm SEM $(n=6)$ of responses on the active lever (black triangles, left Y-axis), responses on the inactive lever (white triangles, left Y-axis), and selectivity for the active lever (gray circles, right Y-axis). The "Pre" data represent the average of the last two sessions of acquisition collected immediately before the extinction phase began. Extinction data were subjected to repeated-measures ANOVA or Friedman's test, and data from the 10th extinction session were compared with data from the last two acquisition sessions (Pre, ${ }^{\#} p<0.05$ ) and from the cue-induced reinstatement session $\left(\mathrm{Cue},{ }^{*} p<0.05\right)$ using paired $t$ tests
$F_{9,45}=2.03, p=0.06$ ), while the number of presses on the inactive lever and the selectivity for the active lever remained stable over time. Accordingly, responding during the last extinction session (session 10) was significantly different from responding during the last two acquisition sessions (indicated as "Pre" in Fig. 6) for active lever presses (paired $t$ test, $t_{5}=2.18, p<0.05$ ) but not for inactive lever presses and selectivity.

Resuming the presentation of the visual stimulus during the reinstatement session increased the number of presses on the active lever (paired $t$ test, $t_{5}=2.35, p<0.05$ ) but did not affect presses on the inactive lever or selectivity for the active lever compared with the last extinction session (Fig. 6).

Analysis of patterns of responding

\section{Analysis of frequency distribution}

Patterns of responding were analyzed to determine whether they could differentiate lever pressing for nicotine from saline- and cue-maintained behavior. For this purpose, the intervals between the end of the time-out period and the first response post-timeout and the intervals preceding the second and third responses post-timeout were examined separately using data from experiment 1 in which an FR3 schedule of reinforcement was used. Responses emitted during the time-out period were not taken into consideration in the analyses reported below. Our results, however, were not significantly affected by the inclusion or exclusion of time-out responses (see Supplementary Figure S3 and Supplementary Results).
The frequency distribution of these two types of IRIs was clearly different, with the second and third IRIs being markedly shorter than the first IRI (Fig. $7 \mathrm{a}$ vs b). Significant differences were detected when comparing the percentages of the two types of intervals that were shorter than $60 \mathrm{~s}$, between 60 and $240 \mathrm{~s}$, or longer than $240 \mathrm{~s}$ for all doses of nicotine analyzed, including saline (two-way repeated-measures ANOVAs, $F_{1,24}=67.42, p<$ $0.001, F_{1,24}=29.42, p<0.001$, and $F_{1,24}=15.80, p<0.001$, respectively).

A main effect of nicotine dose was detected on both short and long intervals $\left(F_{3,24}=4.03, p \leq 0.01\right.$, and $F_{3,24}=$ $5.20, p<0.01$, respectively). Nicotine actually impacted the duration of the first IRI (Supplementary Figure S3 and Fig. 7a) without altering the duration of the second and third IRIs (Supplementary Figure S3 and Fig. 7b). For the first response post-timeout, the relative frequency of short IRIs (below $60 \mathrm{~s}$ ) was dose-dependently decreased by nicotine (Friedman test, $Q_{3}=11.67, p<0.01$ ), an effect mirrored by a concomitant increase in the incidence of long intervals (above $240 \mathrm{~s}$; repeated-measures ANOVA, $F_{3,36}=4.27, p<0.05$ ). Nicotine self-administration, therefore, shifted the interval length toward longer durations, with less than $15 \%$ of the intervals being shorter than $60 \mathrm{~s}$ and half of the intervals being longer than $240 \mathrm{~s}$ for mice self-administering nicotine at a dose of $0.1 \mathrm{mg} / \mathrm{kg} /$ infusion $(p<0.01$, compared with saline; Fig. 7a).

Interestingly, the frequency distribution of the IRIs for the first response following the delivery of the saline infusion (together with the cue light, experiment 1, "Saline+Cue") was similar to the frequency distribution 
Fig. 7 Frequency distribution of IRIs in mice self-

administering different doses of nicotine $(\mathbf{a}, \mathbf{b})$ or cocaine $(\mathbf{c})$ (experiment 1). a Relative frequency of short (below $60 \mathrm{~s}$ ), intermediate (between 60 and $240 \mathrm{~s}$ ), and long (above $240 \mathrm{~s}$ ) intervals between the end of the time-out period and the first response post-timeout. b Relative frequency of short, intermediate, and long intervals preceding the second and third responses post-timeout. Results are expressed as mean \pm SEM $(n=13)$. Data were subjected to one-way repeated-measures ANOVA or Friedman's test, with nicotine dose as the withinsubjects factor, followed by post hoc comparisons with the $0 \mathrm{mg} /$ $\mathrm{kg}$ /infusion dose (saline; $* * p<$ $0.01)$. c Relative frequency of short, intermediate, and long intervals between the end of the time-out period and the first response after infusion in mice self-administering cocaine. Results are expressed as mean \pm SEM $(n=9)$. Data were subjected to Friedman's test, with cocaine dose as the withinsubjects factor, followed by post hoc comparisons with the $0.1 \mathrm{mg} / \mathrm{kg} /$ infusion dose $\left({ }^{\#} p<\right.$ $0.05,{ }^{\# \# \#-0.001)}$ a

First inter-response intervals post-timeout

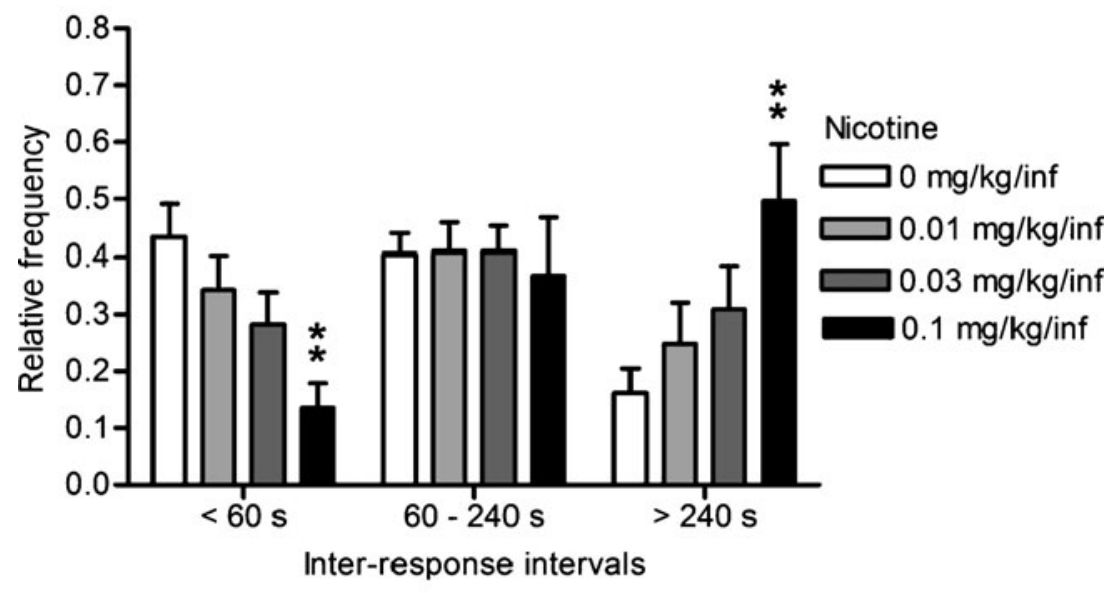

b Second and third inter-response intervals post-timeout
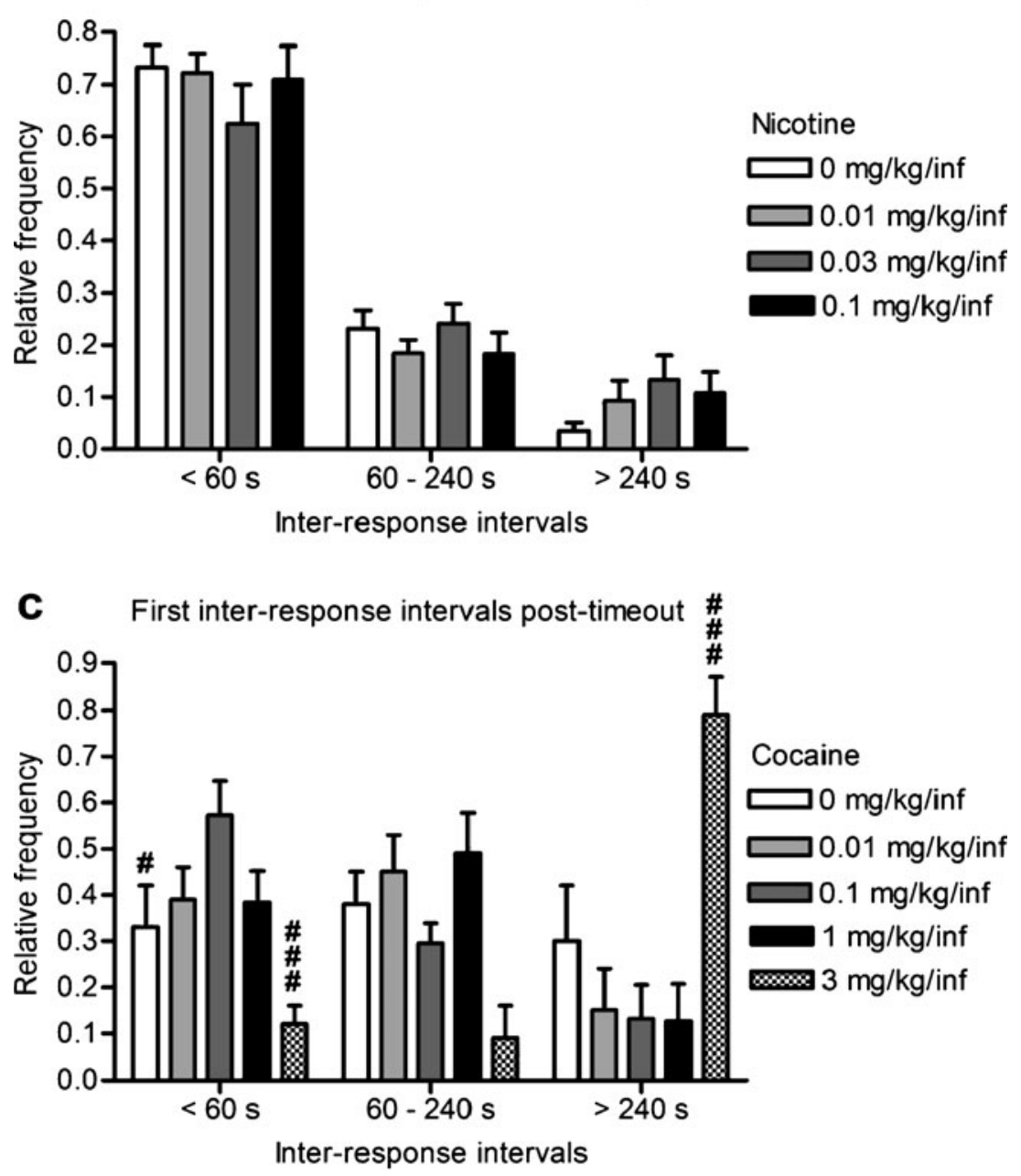

obtained for the first response following presentation of the visual stimulus alone (experiment 3, "Cue only"; see Supplementary Figure S4). No significant differences were detected for any of the intervals when comparing responding for Saline + Cue and Cue alone.
The frequency distribution of IRIs was also analyzed for mice self-administering cocaine in experiment 1 . Doses of cocaine that led to increased response rates compared with saline produced a concomitant shortening of the first IRI, while doses on the descending limb of the inverted U- 
shaped dose-response curve delayed the first response post-timeout (Fig. 7c). A significant effect of cocaine dose was found on the frequency distribution of short (below $60 \mathrm{~s}$, Friedman test, $Q_{4}=23.62, p<0.001$ ), intermediate (between 60 and $240 \mathrm{~s}$, Friedman test, $Q_{4}=11.43, p<0.05$ ), and long (above $240 \mathrm{~s}$, Friedman test, $Q_{4}=23.20, p<0.001$ ) IRIs for the first response post-timeout. Post hoc tests indicated that the relative frequency of the short intervals was increased by the $0.1 \mathrm{mg} / \mathrm{kg} /$ infusion dose of cocaine compared with saline $(p<0.05)$, while it was decreased by the $3 \mathrm{mg} / \mathrm{kg}$ /infusion dose compared with the $0.01,0.1$, and $1 \mathrm{mg} / \mathrm{kg} /$ infusion doses $(p<0.05, p<0.001$, and $p<$ 0.05 , respectively). The latter effect of the $3 \mathrm{mg} / \mathrm{kg} /$ infusion dose was mirrored by a concomitant increase in the frequency of the long intervals compared with the $0.01,0.1$, and $1 \mathrm{mg} / \mathrm{kg} /$ infusion doses $(p<0.05, p<0.001$, and $p<0.01$, respectively).

\section{Return map analysis}

The IRIs were further analyzed for their regularity using return maps. To this end, each IRI $\left(\mathrm{IRI}_{n+3}\right)$ was plotted against the third previous interval $\left(\mathrm{IRI}_{n}\right)$ to take into account the bimodal distribution of IRIs that differentiate the first from the second and third interval post-timeout (see above). Such lag 3 return maps were plotted for each sequence of intervals obtained for different nicotine doses self-administered in experiment $1(0,0.01,0.03$, and $0.1 \mathrm{mg} / \mathrm{kg} /$ infusion). No pattern emerged from the scatter plot generated for any of the nicotine doses (Fig. 8a). Fold 3 and fold 5 extended return maps were therefore plotted, as they are more likely than standard return maps to reveal patterns within highly variable data sets (Fig. 8b and c). Increasing the fold value enhanced the linearity of the scatter plots. Linear regression parameters (slope, Yintercept, goodness of fit) obtained for each nicotine dose were all sensitive to the fold value (two-way ANOVA, $F_{2,6}=255.19, p<0.001, F_{2,6}=26.51, p<0.01, F_{2,6}=725.94$, $p<0.001$, respectively), with the slope approaching 1 , the intercept approaching 0 , and the goodness of fit approaching 1 with each fold increment. Importantly, a main effect of nicotine dose was also found on the slope $\left(F_{3,6}=9.35\right.$, $p<0.05)$ and on the goodness of fit $\left(F_{3,6}=6.78, p<0.05\right)$, with the slope approaching 1 and the goodness of fit approaching 1 with increasing doses of nicotine (see Fig. $8 \mathrm{~b}$ and c). Analysis of individual regression lines confirmed that the slope was closer to 1 (fold 3, Wilcoxon test, $W=-37, p<0.05$ ) and the goodness of fit was closer to 1 (fold 1, Wilcoxon test, $W=-71, p<0.01$; fold 5 , paired $t$ test, $\left.t_{6}=2.23, p<0.05\right)$ with the $0.1 \mathrm{mg} / \mathrm{kg} /$ infusion nicotine dose than with saline. These results suggest that nicotine enhanced the regularity of lever pressing behavior, as it decreased the spread (or diffuseness) of the scatter plot. High doses of nicotine concentrated the dots along a line, instead of within a cluster, because the plotted data sets combined IRIs of disparate durations (see above).

Interestingly, the extended return maps generated for saline-reinforced behavior $(0 \mathrm{mg} / \mathrm{kg} /$ infusion dose of the nicotine dose-response curve in experiment 1 , "Saline+ Cue") were similar to the extended return maps obtained for cue-reinforced behavior (experiment 3, "Cue only"; see Supplementary Figure S5a-c for standard lag 3 return map and fold 3 and fold 5 extended return maps, respectively). Increasing the fold value of the maps likewise enhanced the linearity of the scatter plot (two-way ANOVA, $F_{2,2}=83.08$, $p<0.05$, for the slope; $F_{2,2}=90.76, p<0.05$, for the Yintercept; $F_{2,2}=152.83, p<0.01$, for the goodness of fit), but no main effect of saline infusion was found on any of the linear regression parameters.

An identical return map analysis was conducted for lever pressing activity supported by different doses of cocaine $(0$, $0.01,0.1,1$, and $3 \mathrm{mg} / \mathrm{kg} /$ infusion) in experiment 1 (see Supplementary Figure S6a-c). Similar to the above, the linearity of the scatter plots was sensitive to the fold value and increased with each fold increment (two-way ANOVA, $F_{2,8}=30.76, p<0.001$, for the slope; $F_{2,8}=14.54, p<0.01$, for the Y-intercept; $F_{2,8}=110.93, p<0.001$, for the goodness of fit). However, cocaine did not influence any of the linear regression parameters.

\section{Discussion}

The present study reports the characterization of intravenous nicotine self-administration in $\mathrm{C} 57 \mathrm{BL} / 6 \mathrm{~J}$ mice. Our procedure was based on established protocols of psychostimulant self-administration in mice (Caine et al. 2002; Yan et al. 2006) and nicotine self-administration in rats (Corrigall and Coen 1989; Watkins et al. 1999). Under our experimental conditions, operant responding for nicotine could not be differentiated from saline- or cue lightmaintained behavior in terms of the number of reinforcers earned within a session. Mice self-administering nicotine showed a remarkable selectivity for the active lever, which decreased across the extinction sessions and was restored during the reinstatement test. The selectivity was higher in mice self-administering nicotine than in mice lever pressing exclusively for the visual stimulus alone and tended to be increased by high doses of nicotine. Furthermore, nicotine dose-dependently delayed the emission of the first response post-timeout and enhanced the regularity of lever pressing activity. Our data also provide unambiguous evidence that the visual stimulus itself supports operant responding, in accordance with previous findings (Donny et al. 2003; Olsen and Winder 2009). 
Fig. 8 Return maps of IRIs and running averages in mice selfadministering different doses of nicotine (experiment 1). a Standard (fold 1) lag 3 return map. b Fold 3 extended return map. c Fold 5 extended return map. Data were subjected to linear regression analysis to determine the slope, intercept, and goodness of fit of the best fitting line a

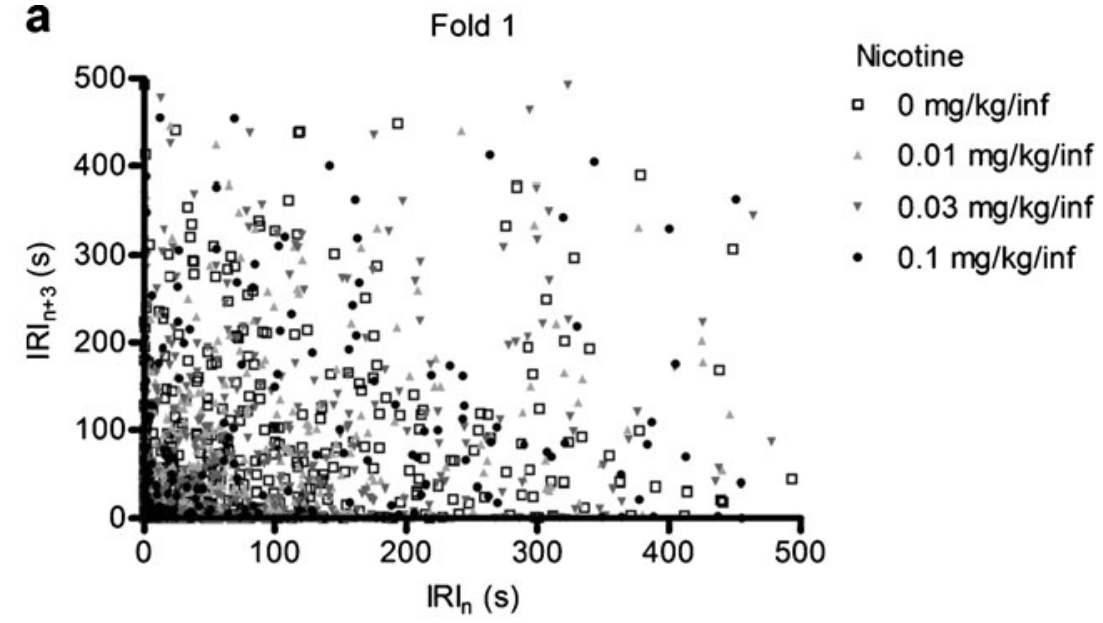

b

Fold 3

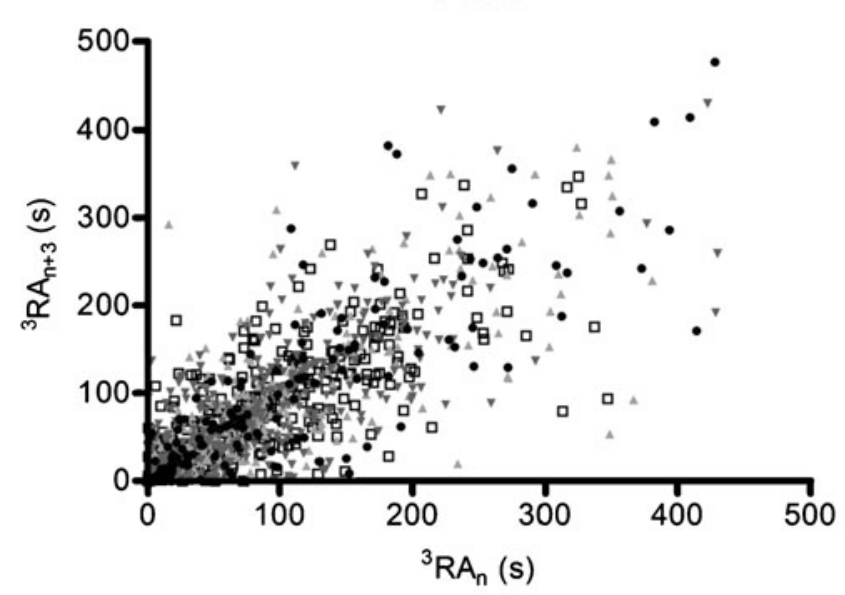

Nicotine

- $0 \mathrm{mg} / \mathrm{kg} / \mathrm{inf}$

4 $0.01 \mathrm{mg} / \mathrm{kg} / \mathrm{inf}$

- $0.03 \mathrm{mg} / \mathrm{kg} / \mathrm{inf}$

- $0.1 \mathrm{mg} / \mathrm{kg} / \mathrm{inf}$
C

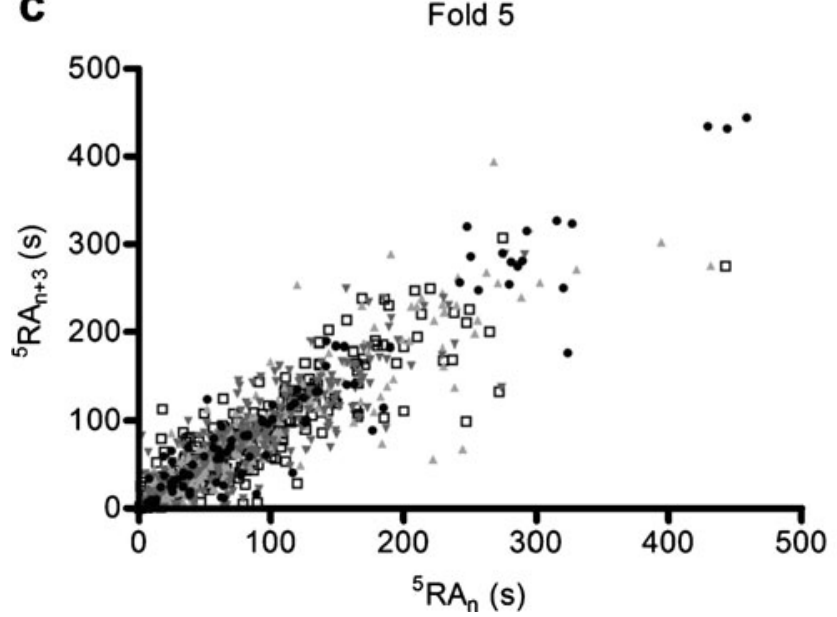

Nicotine

- $0 \mathrm{mg} / \mathrm{kg} / \mathrm{inf}$

4 $0.01 \mathrm{mg} / \mathrm{kg} / \mathrm{inf}$

- $0.03 \mathrm{mg} / \mathrm{kg} / \mathrm{inf}$

- $0.1 \mathrm{mg} / \mathrm{kg} / \mathrm{inf}$
We also demonstrated that, under similar experimental conditions, C57BL/6J mice maintained cocaine, but not nicotine, self-administration above saline-sustained levels. The inverted U-shaped dose-response curve we obtained for cocaine matches previously published data (Caine et al. 1999; Thomsen and Caine 2006), thereby validating our experimental conditions. The nicotine dose-effect function, on the other hand, was flat, except for a decrease in responding at the highest dose tested. This is one of the first reports of a within-subjects dose-response curve for the maintenance of nicotine self-administration using a randomized dose order. An earlier study showed significant self-administration of nicotine at a dose of $0.1 \mathrm{mg} / \mathrm{kg}$ / infusion, but this was the first dose of a descending series to 
be tested directly after water training (Stolerman et al. 1999). An order effect in that study, therefore, may have been responsible for the observed rate of responding above saline-maintained levels. Two more recent studies used a between-subjects design to study the effects of dose on the acquisition of nicotine self-administration (Galeote et al. 2009; Martin-Garcia et al. 2009). Inter-cohort variability, however, limits the interpretability of between-subjects dose-response curves (Martin-Garcia et al. 2009). Data collected under these conditions led to a flat dose-intake relationship reminiscent of the dose-response curve we obtained here, except for a decrease in responding at the lowest dose tested, $0.0052 \mathrm{mg} / \mathrm{kg} /$ infusion (Galeote et al. 2009). Determining whether higher nicotine doses were significantly self-administered in the latter study, however, is difficult because saline was not included in the determination of the dose-response function and statistical analysis of dose effects was not reported. Despite the wide range of doses tested in the present study, no dose of nicotine sustained higher levels of responding than saline in C57BL/6J mice.

Responding on the active lever did not significantly decrease during the extinction phase of nicotine selfadministration, whereas it rapidly declined during extinction of cocaine self-administration. The difference between these two extinction profiles may be attributable to a floor effect, as response rates were markedly higher during cocaine than nicotine self-administration and reached similar levels for both drugs on the last extinction session. In addition, extinction of nicotine seeking may have been hindered by the sustained presence of contextual cues (see Le Foll and Goldberg 2009 for review). Increased responding on the inactive lever and the concomitant decrease in selectivity indicated that the absence of nicotine delivery and contingently paired cues altered the operant behavior of mice that previously self-administered nicotine. Contingent presentation of the visual stimulus reinstated responding on the active lever in both nicotine and cocaine selfadministering mice, and also increased lever selectivity in the case of nicotine. These findings are consistent with previous studies characterizing extinction and cue-induced reinstatement of nicotine and cocaine seeking in mice (Highfield et al. 2002; Martin-Garcia et al. 2009; Soria et al. 2008). Importantly, given that nicotine was no more reinforcing than saline infusions, responding measured during the reinstatement session in mice previously selfadministering nicotine was possibly driven by the reinforcing effects of the visual stimulus, rather than by nicotine seeking. This hypothesis is supported by the insensitivity of responding to withholding and subsequent reinstatement of nicotine delivery when operant responses were still reinforced by cue light presentations (experiment 1, saline substitution phase). Unlike nicotine, withholding cocaine delivery extinguished responding despite the contingent presentation of the cue light.

The above findings did not provide evidence of the positive reinforcing effects of nicotine in terms of response rates. In addition, our preliminary attempts to train mice to self-administer nicotine without the concomitant presentation of a visual stimulus were unsuccessful (data not shown). We therefore assessed whether C57BL/6J mice could acquire operant behavior exclusively motivated by the presentation of the cue light to evaluate the potential contribution of the reinforcing effects of the visual stimulus to the generated nicotine dose-response function. Under comparable experimental conditions, mice were trained to lever press for a visual stimulus (experiment 3) and achieved response rates similar to those achieved by mice self-administering saline or low doses of nicotine in the presence of the cue light (experiments 1 and 2). The latter result indicates that the visual stimulus, rather than other paired environmental cues, such as the syringe pump sound or the interoceptive cues associated with the intravenous injection, motivated the operant behavior sustained by saline infusions. This finding is consistent with a recent report showing that $\mathrm{C} 57 \mathrm{BL} / 6 \mathrm{~J}$ mice readily acquire operant responding for a dynamic visual stimulus (Olsen and Winder 2009). Previous work in rats also demonstrated that a compound visual stimulus can sustain moderate rates of operant responding (Donny et al. 2003). Importantly, in the same study, nicotine $(0.03 \mathrm{mg} / \mathrm{kg} /$ infusion $)$ did not support responding in the absence of the visual stimulus, but the contingent presentation of the visual stimulus with nicotine infusions had a synergistic effect on responding (Donny et al. 2003). Generally, nicotine has been shown to enhance the incentive properties of environmental stimuli associated with its delivery, as well as the effects of other rewarding stimuli, such as intracranial self-stimulation, in rats (Caggiula et al. 2001; Chaudhri et al. 2006; Harrison et al. 2002; Kenny 2007; Kenny and Markou 2006). Under our experimental conditions, nicotine did not enhance the reinforcing value of the visual cue. The low intrinsic reinforcing value of the static visual cue we used, compared with the compound stimulus used in other studies (Donny et al. 2003; Olsen and Winder 2009), may have limited the reward-enhancing effects of nicotine, which are known to depend on the intensity of the primary reinforcer (Palmatier et al. 2007). This interpretation, however, is not consistent with the recent finding that an auditory stimulus, which is not reinforcing by itself, potentiates nicotine selfadministration in rats (Sorge et al. 2009). Alternatively, nicotine may have conferred a strong incentive value to the visual stimulus during the acquisition phase of operant responding when nicotine and the cue were coadministered, which may then have been carried over throughout the experiment, independent of the dose of 
nicotine contingently delivered with the cue during the dose-response phase. Our observation that mice selfadministering saline in the presence of the cue light previously paired with nicotine (experiment 1 ) achieved a better selectivity for the active lever than mice trained to lever press for the visual stimulus alone (experiment 3 ) is indicative of such a protracted effect of nicotine on responding for the visual stimulus. These two groups of mice, however, earned a similar number of reinforcers and displayed undistinguishable patterns of responding. A more likely explanation is that the intrinsic reinforcing properties of our visual stimulus were strong enough to mask any added effects of nicotine. Differences in the rates of responding maintained by intravenous nicotine injections have been previously described between different species of non-human primates (see Le Foll and Goldberg 2009 for review). Thus, it is possible that, among rodents, nicotine reinforcement is not as powerful in mice as it is in rats. In humans, the reinforcing effects of intravenous nicotine infusions have also been disputed and appear to be weaker than the strong reinforcing effects of tobacco smoke (see Le Foll and Goldberg 2009 for review). In addition, studies that directly compared nicotine and cocaine selfadministration in rats and dogs consistently reported that nicotine is a weaker reinforcer than cocaine, in accordance with our finding in mice (see Le Foll and Goldberg 2009 for review).

Although nicotine did not significantly increase the rate of operant responding, it markedly modified the temporal patterns of operant behavior. The analysis of the frequency distribution of the IRIs indicated that the first interval after the infusion of saline, nicotine, or cocaine or the presentation of the cue light alone was longer than the two subsequent intervals. This bimodal distribution of IRIs is characteristic of operant behavior maintained on an FR schedule of reinforcement, in which a post-reinforcement pause precedes a steady rate of responding until the next reinforcer is obtained (Felton and Lyon 1966). The term "post-reinforcement pause" should be used with caution, as (1) our data do not provide evidence of nicotine reinforcement and (2) the post-reinforcement pause was historically characterized with no scheduled time-out period after delivery of the reinforcer. Nonetheless, previous characterization of the post-reinforcement pause can shed some light on our results. Early investigations showed that the duration of the post-reinforcement pause was an increasing function of the magnitude of the preceding reinforcer delivered (Lowe et al. 1974). Characterization of response patterns across a wide range of alfentanil, cocaine, and ketamine doses in monkeys indicated that the post-reinforcement pause was consistently shortened for drug doses corresponding to the ascending limb of the inverted Ushaped dose-response functions, but variably affected along the descending limb (Skjoldager et al. 1991). In the present study, low doses of cocaine $(0.01,0.1$, and $1 \mathrm{mg} / \mathrm{kg} /$ infusion) shortened the first interval post-timeout, while the highest dose tested ( $3 \mathrm{mg} / \mathrm{kg} /$ infusion) dramatically increased its duration, which is consistent with the findings reported by Skjoldager and colleagues. The length of the post-reinforcement pause is determined by a variety of factors. Among these, motor impairment, emergence of aversive effects, self-titration in response to satiation, and pharmacokinetic parameters could all contribute to a lengthening of the post-reinforcement pause by high doses of a drug. Although the role played by each of these factors may be difficult to ascertain, the return map analysis provides evidence that the increase in pause time produced by nicotine is not attributable to a disruption of ongoing response patterns. In contrast, nicotine dose-dependently increased the regularity of lever pressing, as revealed by an increase in the linearity of the scatter plots. The decrease in response rates produced by high doses of nicotine therefore likely reflects an enhancement of the discriminative effects of nicotine, which in turn improves performance precision. This interpretation is consistent with our observations that mice trained to self-administer nicotine achieved a higher selectivity for the active lever than mice trained to lever press for the cue light alone (experiment 1 vs experiment 3 ) and that high doses of nicotine tended to increase the selectivity for the active lever (see combined analysis of experiments 1 and 2). Taken together, the results of the present study indicate that the interoceptive cue state produced by high doses of nicotine functions as a powerful salient stimulus that concomitantly leads to a decrease in response rates and an increase in the regularity of operant activity.

Interestingly, this result may have some relevance to smoking behavior in humans. The invariance of smoking patterns is positively correlated with the number of cigarettes smoked per day, which is consistent with our finding that nicotine dose-dependently reduces the flexibility of self-administration patterns (Clark et al. 2005; Okuyemi et al. 2007; Shiffman et al. 2004). Importantly, the rigidity of smoking patterns also predicts DSM-IV dependence and failure of smoking cessation (Broms et al. 2007; Shiffman et al. 2004).

It has been recognized early on that the experimental conditions under which nicotine serves as a reinforcer are more restricted than for other drugs of abuse, both in human subjects and in laboratory animals (Henningfield and Goldberg 1983). Below, we discuss the rationale behind our experimental procedure and what approaches could be taken to overcome its limitations so as to detect higher response rates in mice self-administering nicotine than in mice responding for saline infusions or for cue light presentations. 
We chose not to use an alternative reinforcer for the shaping of the operant response to ensure that nicotine was the sole rewarding stimulus reinforcing lever pressing behavior. The use of cocaine to enhance self-administration acquisition, as reported in earlier studies (Epping-Jordan et al. 1999; Picciotto et al. 1998), is questionable, since cocaine exposure is likely to alter the function of brain reward circuitries. Accordingly, initial experience with cocaine influenced response rates and patterns in monkeys subsequently self-administering opiates (Hoffmeister and Schlichting 1972). Prior operant training with non-drug reinforcers, such as water (Stolerman et al. 1999) or food (Bilkei-Gorzo et al. 2008), may likewise alter subsequent responding for nicotine. In particular, because of the limited primary reinforcing effect of nicotine, prior instrumental learning with strong reinforcers, such as cocaine, water in thirsty animals, or food in hungry animals, before switching to nicotine reinforcement may result in habit learning that perpetuates high levels of operant behavior that are dissociated from the incentive value of the available reinforcer (Dickinson et al. 2002; Miles et al. 2003). Nicotine self-administration procedures used in rats typically include a food training phase, which does not prevent dose-dependent effects of nicotine on response rates (Corrigall and Coen 1989; Donny et al. 1998; Watkins et al. 1999). Under certain experimental conditions, however, prior instrumental training with a natural reinforcer can have confounding effects on subsequent responding for saline or nicotine and can lastingly enhance the reinforcing properties of the visual stimulus (Clemens et al. 2010).

We employed food restriction to stimulate exploratory activity in the self-administration chamber and enhance acquisition of nicotine self-administration, as previously shown in rats (Donny et al. 1998; Lang et al. 1977). Dietary restriction may have actually prevented us from detecting enhanced responding for nicotine because excessive general activity, manifested by high lever pressing activity for saline, could have masked further increases in operant behavior. Providing mice with ad libitum access to food may facilitate a nicotine-induced increase in response rates. Shifting the self-administration session to a low-activity period of the circadian cycle (light phase) could be an alternative way to lower basal responding and facilitate the expression of nicotine-specific behavior, although the stimulant properties of nicotine may artificially increase lever pressing activity independent of its reinforcing effects. Importantly, the lack of differences in response rates maintained by nicotine relative to saline is unlikely to be solely attributable to excessive basal activity because a similar number of reinforcers was obtained under FR1 and FR3 schedules of reinforcement (experiments 1 and 2), indicating that mice adjusted their responding based on the FR.
We attempted to optimize conditions to measure purposeful, goal-directed behavior by using lever pressing instead of nose-poking as the instrumental response and by using an FR3 instead of a continuous schedule of reinforcement. These experimental conditions differ from those that have been used previously in most studies assessing nicotine self-administration in mice (Bilkei-Gorzo et al. 2008; Galeote et al. 2009; Martin-Garcia et al. 2009). Interestingly, the more stringent response requirements used in the present study did not prevent mice from acquiring operant behavior. We show here that the performance of mice self-administering nicotine under FR1 and FR3 schedules of reinforcement was indistinguishable in terms of response rates and selectivity for the active lever (experiments 1 and 2). This result is consistent with a previous study showing that mice self-administered nicotine using lever pressing as the instrumental response and an FR4 schedule of reinforcement (Stolerman et al. 1999). Relatively demanding response requirements constitute an important condition to demonstrate that mice exhibit purposeful self-administration behavior. Operant responses requiring less effort, such as nose-poking, may result in higher response rates but also in higher levels of inactive and time-out responses, as was shown in rats selfadministering nicotine (Clemens et al. 2010). Finally, the use of a non-continuous schedule of reinforcement produces patterns of responding whose analysis provides additional important insights into motivated behavior (see above).

The duration of the infusion is another parameter that should be taken into consideration. It is striking that C57BL/6J mice self-administered nicotine at an optimal dose of $0.1 \mathrm{mg} / \mathrm{kg} /$ infusion when infusions were delivered over a period of $7.5 \mathrm{~s}$ (Stolerman et al. 1999), while this dose reproducibly produced decreased responding under our experimental conditions (1-s infusions). The speed of nicotine infusion delivery is a critical determinant of nicotine self-administration pharmacology (Sorge and Clarke 2009), and slower infusions may not only be more relevant to arterial nicotine kinetics in human smokers (Rose et al. 1999) but also favor the acquisition of nicotine self-administration in rats (Sorge and Clarke 2009). In addition, the pharmacokinetics of nicotine markedly differ in mice and rats. $\mathrm{C} 57 \mathrm{BL} / 6 \mathrm{~J}$ mice eliminate nicotine with a half-life of $7 \mathrm{~min}$, which is 10 times faster than in rats (Kyerematen et al. 1988; Miller et al. 1977; Petersen et al. 1984). This disparity may significantly impact the doseresponse curve for nicotine self-administration, and the optimal training dose may therefore be higher for mice than for rats.

In conclusion, under the experimental conditions used in the present study for intravenous nicotine self-administration in C57BL/6J mice, nicotine does not appear to enhance the reinforcing properties of the visual cue associated with its 
delivery, but it acts as a powerful salient stimulus driving unique patterns of operant responding. In contrast to operant behavior sustained by the sole presentation of a visual stimulus, high doses of nicotine enhanced the specificity for the active lever, delayed the first response post-timeout, and increased the regularity of lever pressing behavior. Further parametric investigation is required to discover experimental conditions under which nicotine produces higher response rates than saline or the visual cue alone in mice.

Acknowledgements This work was supported by National Institutes of Health grants R01DA023209 to AM and R01DA020686 to PJK. $\mathrm{CC}$ was partially supported by a postdoctoral fellowship from the Fondation pour la Recherche Médicale, France (SPE20060908085).

Conflict of interest None to declare.

Open Access This article is distributed under the terms of the Creative Commons Attribution Noncommercial License which permits any noncommercial use, distribution, and reproduction in any medium, provided the original author(s) and source are credited.

\section{References}

Adriani W, Macri S, Pacifici R, Laviola G (2002) Restricted daily access to water and voluntary nicotine oral consumption in mice: methodological issues and individual differences. Behav Brain Res 134:21-30

Bilkei-Gorzo A, Racz I, Michel K, Darvas M, Maldonado R, Zimmer A (2008) A common genetic predisposition to stress sensitivity and stress-induced nicotine craving. Biol Psychiatry 63:164-171

Broms U, Madden PA, Heath AC, Pergadia ML, Shiffman S, Kaprio J (2007) The nicotine dependence syndrome scale in Finnish smokers. Drug Alcohol Depend 89:42-51

Caggiula AR, Donny EC, White AR, Chaudhri N, Booth S, Gharib MA, Hoffman A, Perkins KA, Sved AF (2001) Cue dependency of nicotine self-administration and smoking. Pharmacol Biochem Behav 70:515-530

Caine SB, Negus SS, Mello NK (1999) Method for training operant responding and evaluating cocaine self-administration behavior in mutant mice. Psychopharmacology (Berl) 147:22-24

Caine SB, Negus SS, Mello NK, Patel S, Bristow L, Kulagowski J, Vallone D, Saiardi A, Borrelli E (2002) Role of dopamine D2like receptors in cocaine self-administration: studies with D2 receptor mutant mice and novel D2 receptor antagonists. J Neurosci 22:2977-2988

Chaudhri N, Caggiula AR, Donny EC, Palmatier MI, Liu X, Sved AF (2006) Complex interactions between nicotine and nonpharmacological stimuli reveal multiple roles for nicotine in reinforcement. Psychopharmacology (Berl) 184:353-366

Clark DB, Wood DS, Martin CS, Cornelius JR, Lynch KG, Shiffman S (2005) Multidimensional assessment of nicotine dependence in adolescents. Drug Alcohol Depend 77:235-242

Clemens KJ, Caille S, Cador M (2010) The effects of response operandum and prior food training on intravenous nicotine selfadministration in rats. Psychopharmacology (Berl) 211(1):43-54

Corrigall WA, Coen KM (1989) Nicotine maintains robust selfadministration in rats on a limited-access schedule. Psychopharmacology (Berl) 99:473-478
Criswell HE (1982) A simple methodology for opiate selfadministration and electrical brain stimulation in the mouse. Life Sci 31:2391-2394

Dickinson A, Wood N, Smith JW (2002) Alcohol seeking by rats: action or habit? Q J Exp Psychol B 55:331-348

Donny EC, Caggiula AR, Mielke MM, Jacobs KS, Rose C, Sved AF (1998) Acquisition of nicotine self-administration in rats: the effects of dose, feeding schedule, and drug contingency. Psychopharmacology (Berl) 136:83-90

Donny EC, Chaudhri N, Caggiula AR, Evans-Martin FF, Booth S, Gharib MA, Clements LA, Sved AF (2003) Operant responding for a visual reinforcer in rats is enhanced by noncontingent nicotine: implications for nicotine self-administration and reinforcement. Psychopharmacology (Berl) 169:68-76

Epping-Jordan MP, Picciotto MR, Changeux JP, Pich EM (1999) Assessment of nicotinic acetylcholine receptor subunit contributions to nicotine self-administration in mutant mice. Psychopharmacology (Berl) 147:25-26

Felton M, Lyon DO (1966) The post-reinforcement pause. J Exp Anal Behav 9:131-134

Galeote L, Berrendero F, Bura SA, Zimmer A, Maldonado R (2009) Prodynorphin gene disruption increases the sensitivity to nicotine self-administration in mice. Int $\mathrm{J}$ Neuropsychopharmacol 12:615-625

Harrison AA, Gasparini F, Markou A (2002) Nicotine potentiation of brain stimulation reward reversed by DH beta E and SCH 23390 , but not by eticlopride, LY 314582 or MPEP in rats. Psychopharmacology (Berl) 160:56-66

Hatsukami DK, Stead LF, Gupta PC (2008) Tobacco addiction. Lancet 371:2027-2038

Henningfield JE, Goldberg SR (1983) Nicotine as a reinforcer in human subjects and laboratory animals. Pharmacol Biochem Behav 19:989-992

Highfield DA, Mead AN, Grimm JW, Rocha BA, Shaham Y (2002) Reinstatement of cocaine seeking in $129 \mathrm{X} 1 / \mathrm{SvJ}$ mice: effects of cocaine priming, cocaine cues and food deprivation. Psychopharmacology (Berl) 161:417-424

Hoffmeister F, Schlichting UU (1972) Reinforcing properties of some opiates and opioids in rhesus monkeys with histories of cocaine and codeine self-administration. Psychopharmacologia 23:55-74

Kenny PJ (2007) Brain reward systems and compulsive drug use. Trends Pharmacol Sci 28:135-141

Kenny PJ, Markou A (2006) Nicotine self-administration acutely activates brain reward systems and induces a long-lasting increase in reward sensitivity. Neuropsychopharmacology 31:1203-1211

Kyerematen GA, Taylor LH, deBethizy JD, Vesell ES (1988) Pharmacokinetics of nicotine and 12 metabolites in the rat. Application of a new radiometric high performance liquid chromatography assay. Drug Metab Dispos 16:125-129

Lang WJ, Latiff AA, McQueen A, Singer G (1977) Self administration of nicotine with and without a food delivery schedule. Pharmacol Biochem Behav 7:65-70

Le Foll B, Goldberg SR (2009) Effects of nicotine in experimental animals and humans: an update on addictive properties. Handb Exp Pharmacol 335-367

Li JS, Huston JP (2002) Non-linear dynamics of operant behavior: a new approach via the extended return map. Rev Neurosci 13:3157

Lowe CF, Davey GC, Harzem P (1974) Effects of reinforcement magnitude on interval and ratio schedules. J Exp Anal Behav 22:553-560

Markou A (2008) Review. Neurobiology of nicotine dependence. Philos Trans R Soc Lond B Biol Sci 363:3159-3168 
Martellotta MC, Kuzmin A, Zvartau E, Cossu G, Gessa GL, Fratta W (1995) Isradipine inhibits nicotine intravenous self-administration in drug-naive mice. Pharmacol Biochem Behav 52:271-274

Martin-Garcia E, Barbano MF, Galeote L, Maldonado R (2009) New operant model of nicotine-seeking behaviour in mice. Int $\mathrm{J}$ Neuropsychopharmacol 12:343-356

McDonald JH (2009) Handbook of biological statistics, 2nd edn. Sparky House Publishing, Baltimore, Maryland

Miles FJ, Everitt BJ, Dickinson A (2003) Oral cocaine seeking by rats: action or habit? Behav Neurosci 117:927-938

Miller RP, Rotenberg KS, Adir J (1977) Effect of dose on the pharmacokinetics of intravenous nicotine in the rat. Drug Metab Dispos 5:436-443

Okuyemi KS, Pulvers KM, Cox LS, Thomas JL, Kaur H, Mayo MS, Nazir N, Etter JF, Ahluwalia JS (2007) Nicotine dependence among African American light smokers: a comparison of three scales. Addict Behav 32:1989-2002

Olsen CM, Winder DG (2009) Operant sensation seeking engages similar neural substrates to operant drug seeking in C57 mice. Neuropsychopharmacology 34:1685-1694

Palmatier MI, Matteson GL, Black JJ, Liu X, Caggiula AR, Craven L, Donny EC, Sved AF (2007) The reinforcement enhancing effects of nicotine depend on the incentive value of non-drug reinforcers and increase with repeated drug injections. Drug Alcohol Depend 89:52-59

Paterson NE, Semenova S, Gasparini F, Markou A (2003) The mGluR5 antagonist MPEP decreased nicotine self-administration in rats and mice. Psychopharmacology (Berl) 167:257-264

Petersen DR, Norris KJ, Thompson JA (1984) A comparative study of the disposition of nicotine and its metabolites in three inbred strains of mice. Drug Metab Dispos 12:725-731

Picciotto MR, Zoli M, Rimondini R, Lena C, Marubio LM, Pich EM, Fuxe K, Changeux JP (1998) Acetylcholine receptors containing the beta2 subunit are involved in the reinforcing properties of nicotine. Nature 391:173-177

Plaza-Zabala A, Martin-Garcia E, de Lecea L, Maldonado R, Berrendero F (2010) Hypocretins regulate the anxiogenic-like effects of nicotine and induce reinstatement of nicotine-seeking behavior. J Neurosci 30:2300-2310

Robinson SF, Marks MJ, Collins AC (1996) Inbred mouse strains vary in oral self-selection of nicotine. Psychopharmacology (Berl) 124:332-339

Rose JE, Behm FM, Westman EC, Coleman RE (1999) Arterial nicotine kinetics during cigarette smoking and intravenous nicotine administration: implications for addiction. Drug Alcohol Depend 56:99-107

Semenova S, Kuzmin A, Zvartau E (1995) Strain differences in the analgesic and reinforcing action of morphine in mice. Pharmacol Biochem Behav 50:17-21

Shiffman S, Waters A, Hickcox M (2004) The nicotine dependence syndrome scale: a multidimensional measure of nicotine dependence. Nicotine Tob Res 6:327-348

Skjoldager P, Winger G, Woods JH (1991) Analysis of fixed-ratio behavior maintained by drug reinforcers. J Exp Anal Behav 56:331-343

Sorge RE, Clarke PB (2009) Rats self-administer intravenous nicotine delivered in a novel smoking-relevant procedure: effects of dopamine antagonists. J Pharmacol Exp Ther 330: 633-640

Sorge RE, Pierre VJ, Clarke PB (2009) Facilitation of intravenous nicotine self-administration in rats by a motivationally neutral sensory stimulus. Psychopharmacology (Berl) 207(2):191-200

Soria G, Barbano MF, Maldonado R, Valverde O (2008) A reliable method to study cue-, priming-, and stress-induced reinstatement of cocaine self-administration in mice. Psychopharmacology (Berl) 199:593-603

Stolerman IP, Jarvis MJ (1995) The scientific case that nicotine is addictive. Psychopharmacology (Berl) 117:2-10, discussion 1420

Stolerman IP, Naylor C, Elmer GI, Goldberg SR (1999) Discrimination and self-administration of nicotine by inbred strains of mice. Psychopharmacology (Berl) 141:297-306

Thomsen M, Caine SB (2006) Cocaine self-administration under fixed and progressive ratio schedules of reinforcement: comparison of C57BL/6J, 129X1/SvJ, and 129S6/SvEvTac inbred mice. Psychopharmacology (Berl) 184:145-154

Watkins SS, Epping-Jordan MP, Koob GF, Markou A (1999) Blockade of nicotine self-administration with nicotinic antagonists in rats. Pharmacol Biochem Behav 62:743-751

WHO (2008) WHO report on the global tobacco epidemic, 2008. The MPOWER package. World Health Organization, Geneva

Williams MJ, Adinoff B (2008) The role of acetylcholine in cocaine addiction. Neuropsychopharmacology 33:1779-1797

Yan Y, Nitta A, Mizoguchi H, Yamada K, Nabeshima T (2006) Relapse of methamphetamine-seeking behavior in C57BL/6J mice demonstrated by a reinstatement procedure involving intravenous self-administration. Behav Brain Res 168:137143 